(c) American Dairy Science Association, 2004.

\title{
Purification and Characterization of Three Different Types of Bile Salt Hydrolases from Bifidobacterium Strains
}

\author{
G.-B. Kim, ${ }^{1}$ S.-H. Yi, ${ }^{1}$ and B. H. Lee ${ }^{1,2}$ \\ 'Department of Food Science and Agricultural Chemistry, \\ McGill University, 21,111 Lakeshore Road, \\ Ste-Anne-de-Bellevue, QC, Canada H9X 3V9 \\ ${ }^{2}$ Food Research \& Development Centre, \\ Agriculture and Agri-Food Canada, St-Hyacinthe, \\ QC, Canada J2S 8E3
}

\begin{abstract}
Bile salt hydrolases were purified to electrophoretic homogeneity from Bifidobacterium bifidum ATCC 11863, Bifidobacterium infantis KL412, Bifidobacterium longum ATCC 15708, Bifidobacterium longum KL507, and Bifidobacterium longum KL515. Three different types (A, B, and C) of bile salt hydrolase (BSH) were revealed during the purification study, exhibiting the type-specific characteristics in their electrophoretic migration and elution profiles from anion exchange and hydrophobic interaction chromatographic columns. The subunit molecular mass estimated by sodium dodecylsulfate (SDS)-polyacrylamide gel electrophoresis (PAGE) was around $35 \mathrm{kDa}$, and the native molecular mass in all five Bifidobacterium strains was estimated to be between 130 and $150 \mathrm{kDa}$ by gel filtration chromatography, indicating that all BSH enzymes have tetrameric structure. From the isoelectric focusing, an isoelectric point value of 4.45 was obtained with $\mathrm{BSH}$ (type B) from B. bifidum ATCC 11863 and the other BSH (types A and C) showed the similar pI values around 4.65. N-Terminal amino acid sequencing for the proteins of types $\mathrm{A}$ and $\mathrm{C}$ revealed that 6 out of 20 amino acid residues were different, and highly conserved residues were identified in both $\mathrm{N}$-terminal sequences of types A and C. All BSH enzymes from five strains hydrolyzed six major human bile salts, and they showed a better deconjugation rate on glycine-conjugated bile salts than on taurine-conjugated forms.
\end{abstract}

(Key words: bile salt hydrolase, purification, Bifidobacterium)

Abbreviation key: BSH = bile salt hydrolase, FPLC = fast protein liquid chromatography, HIC = hydrophobic interaction chromatography, IEC = ion-exchange chro-

Received May 13, 2003.

Accepted July 23, 2003.

Corresponding author: B. H. Lee; e-mail: blee@macdonald. mcgill.ca. matography, IEF = isoelectric focusing, $\mathbf{L A B}=$ lactic acid bacteria, $\mathbf{p I}=$ isoelectric point, $\mathbf{S E C}=$ size exclusion chromatography.

\section{INTRODUCTION}

Bifidobacteria are one of the most predominant microflora in the gastrointestinal tracts of humans, and many bifidobacteria-containing dairy and pharmaceutical products have been developed and consumed for several decades due to their reported health-promoting effects. In the gastrointestinal tract, many endogenous microflora and exogenous bacteria continuously encounter a significant amount of bile salts that possess some detergent-like antimicrobial properties (Gunn, 2000). As a consequence, many enteric bacteria have developed mechanisms to resist the detergent action of bile salts and evolved the ability to transform bile salts biochemically. One important enzymatic activity of intestinal bacteria, including bifidobacteria, is the deconjugation of bile salts, and this occurs naturally in the intestinal tract of human and animal. Bile salt hydrolase (BSH, EC 3.5.1.24), which is also called cholylglycine hydrolase, is an enzyme that catalyzes the hydrolysis of glycine- and/or taurine-conjugated bile salts into amino acid residues and free bile acids. Even though it is well known that this enzymatic activity is widely spread among many enteric bacteria, the functions of this enzyme in producing bacterium (as well as) in the mammal host and the precise physiological impact on which the enzymatic products exert their effect are not clearly understood. From a positive viewpoint, it was proposed that high BSH-activity in the probiotic cultures could be beneficial because they have the potential to reduce serum cholesterol (Anderson and Gilliland, 1999; Pereira and Gibson, 2002). Removal of the amino acid moiety from bile salts by deconjugation generates less water-soluble compounds and is easily excreted via feces (De Smet et al., 1998). This drain on the bile salt pool could result in a loss of feedback inhibition on the de novo synthesis of bile salts from 
cholesterol. It has been observed that oral administration of a BSH-active Lactobacillus strain lowered the serum cholesterol levels in animal trials (De Rodas et al., 1996; De Smet et al., 1998; du Toit et al., 1998). Although the potentially positive aspects of probiotic BSH activity have been discussed, other possible negative concerns on BSH activity have become evident recently. Deconjugated bile salts are thought to be the cause of gallstones (Thomas et al., 2000). They can be responsible for depression of growth in chickens due to the poor lipid uptake in the small intestine (Knarreborg et al., 2002) and may cause colorectal cancer because some of the bile salts generated by microbial transformation have been incriminated in colonic carcinogenesis (Singh et al., 1997). Furthermore, it has been proposed that the BSH activity from the virulent strains of Listeria monocytogenes contribute to the virulence factor (Dussurget et al., 2002).

Recent screening analyses with many lactic acid bacteria (LAB) strains, conducted in our laboratory as well as others, revealed that BSH activity is widely distributed in many species of lactobacilli including Lactobacillus acidophilus (Corzo and Gilliland, 1999; Kim et al., 1999; Ahn et al., 2003), Lactobacillus johnsonii (Elkins and Savage, 1998), Lactobacillus gasseri (Usman and Hosono, 1999), and Lactobacillus plantarum (De Smet et al., 1994) and almost every species of Bifidobacterium (Tanaka et al., 1999; Grill et al., 2000b). Interestingly, many strains of bifidobacteria possess higher BSH activity than other probiotics. In spite of this wide distribution and high activity of BSH enzyme in bifidobacteria, only $2 \mathrm{BSH}$ have been purified so far from B. longum BB536 (Grill et al., 1995b) and B. longum SBT 2928 (Tanaka et al., 2000).

To investigate some biochemical characteristics of BSH in Bifidobacterium spp., BSH were purified from B. bifidum ATCC 11863, B. infantis KL412, B. longum ATCC 15708, B. longum KL507, and B. longum KL515. From the profiles of native PAGE followed by BSH activity staining and the elution profiles from an anionexchange column, three types (A, B, and $\mathrm{C}$ ) of $\mathrm{BSH}$ enzyme were identified. Some properties and purification methods of 3 different types of BSH from bifidobacterial strains are described in this study.

\section{MATERIALS AND METHODS}

\section{Source and Maintenance of Cultures}

Among 40 strains of bifidobacteria tested for their BSH activity, 5 strains were selected for this study based on their high BSH enzyme activity and some characteristics from previous screening experiments. Authentic strains, B. bifidum ATCC 11863 and B. longum ATCC 15708, were obtained from the American
Type Culture Collection (Rockville, MD). Bifidobacterium infantis $\mathrm{KL} 412$, B. longum KL507, and B. longum KL515 were obtained from the stock culture collection of the Food R \& D Centre, Agriculture and Agri-Food Canada (Ste-Hyacinthe, QC, Canada). All strains were cultured anaerobically for 24 to $36 \mathrm{~h}$ at $37^{\circ} \mathrm{C}$ in MRS broth (Difco Laboratories, Detroit, MI).

\section{Enzyme and Protein Assays}

The cell-free extracts were prepared by sonicator (Sonic Dismembrator 550, Fisher Scientific, Mississauga, ON, Canada) for 5 min at level 4 under constant cooling. The supernatant was collected by centrifugation $(15,000 \times g, 30 \mathrm{~min})$ and stored at $-20^{\circ} \mathrm{C}$. The $\mathrm{BSH}$ activity was determined by measuring the amount of amino acids resulting from hydrolysis of the amide bond of bile salts using a ninhydrin assay (Tanaka et al., 2000). The hydrolysis rate of conjugated bile salts at $37^{\circ} \mathrm{C}$ was measured in a sodium phosphate buffer $(0.1$ $M, \mathrm{pH}$ 6.5). One unit of BSH activity was defined as the amount of enzyme that liberated $1 \mu \mathrm{mol}$ of amino acid from the substrate per minute. Specific activity was defined as units/mg of protein. Protein concentrations were determined by the Bio-Rad protein assay (BioRad, Mississauga, ON, Canada) using BSA (Sigma Chemical Co., St. Louis, MO) as a standard.

\section{Activity Staining on Acrylamide Gel}

The crude enzymes were loaded and electrophoresed in a nondenaturing $10 \%$ (wt/vol) acrylamide gel with Laemmli buffer (Laemmli, 1970) omitting the SDS (Grill et al., 2000a). Partially purified CBAH (cholylglycine hydrolase) originating from Clostridium perfringens was purchased from Sigma Chemical Co. For comparison purposes, some BSH-positive strains of Lactobacillus species were selected, and their cell-free extracts were prepared. Bile salt hydrolase activity on the gel was detected by washing in a $0.4 M$ sodium acetate buffer $(\mathrm{pH} 4.5)$ and then incubating the gel at $37^{\circ} \mathrm{C}$ in a reaction mixture $(10 \mathrm{~m} M$ sodium taurodeoxycholate in $50 \mathrm{mM}$ sodium phosphate buffer, $\mathrm{pH}$ 5.5). The BSH activity band in the gel was identified by the formation of a white precipitate of deoxycholic acid at the position of the enzyme.

\section{Enzyme Purification}

Hydrophobic interaction chromatography (HIC). The cell-free extracts were precipitated at $4^{\circ} \mathrm{C}$ with ammonium sulfate (40 to $80 \%$ saturation); the pellet was resuspended in a $50 \mathrm{~m} M$ sodium phosphate buffer $(\mathrm{pH}$ 7.0). Portions (1 mL) of concentrated sample were ap- 
plied to HIC columns (HiTrap Phenyl FF or HiTrap Octyl FF, Amersham Pharmacia Biotech Inc., Baie d'Urfé, Québec, Canada) and eluted at a flow rate of 1 $\mathrm{mL} / \mathrm{min}$ by a linear ammonium sulfate gradient $(0.8$

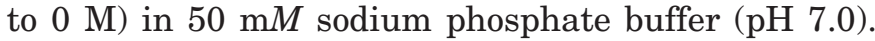
Fractions $(2 \mathrm{~mL})$ were collected and assayed for BSH activity.

Anion-exchange chromatography. The active $\mathrm{BSH}$ fractions from HIC were pooled, desalted, and further concentrated using the Ultrafree- 15 centrifugal filter unit (30 MWCO, Millipore; www.millipore.com). The active fraction obtained from HIC was applied to an anionic-exchange column (Mono Q HR 5/5, Amersham Pharmacia Biotech Inc.) equilibrated with buffer A (50 $\mathrm{m} M$ bis-Tris propane buffer, $\mathrm{pH}$ 6.5). Elution was performed using a linear gradient of $1 M$ sodium chloride in buffer $\mathrm{A}$ at a flow rate of $0.5 \mathrm{~mL} / \mathrm{min}$, and $1-\mathrm{mL}$ fractions were collected. Fractions exhibiting BSH activity were pooled and assayed for protein and enzymatic activity.

\section{Enzyme Purity and Molecular Mass Estimation}

Protein purity and subunit molecular mass were estimated by subjecting aliquots from each purification step to SDS-PAGE using prestained marker proteins (New England BioLabs Inc., Mississauga, Ontario, Canada). Gels were stained with Coomassie brilliant blue R-250. The native molecular mass was determined by gel filtration chromatography (Superose 12 HR 10/30, Amersham Pharmacia Biotech Inc.) using LMW and HMW gel filtration calibration kits purchased from Amersham Pharmacia Biotech Inc. The mobile phase used was $0.1 M$ sodium phosphate- $0.15 M \mathrm{NaCl}$ ( $\mathrm{pH} 7.0$ ), and the flow rate was $0.5 \mathrm{ml} / \mathrm{min}$.

\section{Determination of Isoelectric Point (pl)}

To determine the isoelectric point of $\mathrm{BSH}$ enzymes, the purified enzymes were applied to an isoelectric focusing unit (IEF) (Multiphore II IEF system, Amersham Pharmacia Biotech Inc.) equipped with Immobiline DryStrip. A broad $\mathrm{pH}$ range strip ( $\mathrm{pH} 4.0$ to 7.0, $13 \mathrm{~cm}$ ) was used for the first isoelectric focusing (IEF), and a narrow $\mathrm{pH}$ range strip $(\mathrm{pH} 4.0$ to $5.0,18 \mathrm{~cm})$ was used for the second IEF to measure their precise isoelectric points.

\section{Determination of the $\mathrm{N}$-Terminal Amino Acid Sequence}

Bile salt hydrolase was purified by consecutive HIC and Mono Q chromatography. The resulting active fractions were pooled, concentrated, and applied to a mini electrophoresis unit (Bio-Rad). After separation, the proteins were transferred onto a polyvinylidene fluoride membrane and stained with Coomassie brilliant blue R-250, and the BSH protein was cut out and used for sequencing. N-Terminal amino acid sequencing was performed with a Procise Protein Sequencing System (Applied Biosystems, Foster City, CA).

\section{Substrate Specificity}

To determine the substrate specificity of purified enzymes, the six major human bile salts were selected (Tanaka et al., 2000). Glycocholic acid, glycodeoxycholic acid, glycocheno deoxycholic acid, taurocholic acid, taurodeoxycholic acid, and taurochenodeoxycholic acid were obtained from Sigma Chemical Co. The rate of hydrolysis of conjugated bile salts was measured at $37^{\circ} \mathrm{C}$ and at $\mathrm{pH} 6.5$, which is similar to that of the small intestine in a healthy human (Corzo and Gilliland, 1999). The released amount of amino acid from the substrates by enzymatic reaction was measured by ninhydrin assay and compared with the standard curve prepared by using either glycine or taurine. These experiments were conducted in triplicate.

\section{RESULTS}

\section{Electrophoretic Mobility of BSH}

Native gel electrophoresis followed by BSH activity staining demonstrated that BSH electrophoretic mobility was different according to the origin of the enzymes (Figure 1). Partially purified BSH from Clostridium perfringens (Sigma Chemical Co.) showed the lowest migration among the enzymes tested (lane 1). The highest migration was shown from the BSH enzyme of $B$. infantis KL 412 (lane 2), and a very similar pattern was observed from the BSH of B. longum KL 515. Another distinct migration pattern was identified from the $\mathrm{BSH}$ of B. longum ATCC 15708 and B. longum KL 507 (lane 3). The BSH from B. bifidum ATCC 11863 showed very similar electrophoretic mobility to lane 3 . Based on the electrophoretic mobility of BSH enzymes, 5 strains were separated into 2 different types (type C: $B$. infantis $\mathrm{KL}$ 412 and B. longum KL 515; type A: B. bifidum ATCC 11863, B. longum ATCC 15708, and B. longum KL 507).

Concerning the electrophoretic mobility of $\mathrm{BSH}$ from the genus Lactobacillus, different patterns were observed depending on the strains. Four distinct classes were identified among those tested in this experiment (lanes 4 through 7).

\section{Purification of BSH}

To investigate the biochemical characteristics of the enzymes, BSH of bifidobacterial strains were purified 


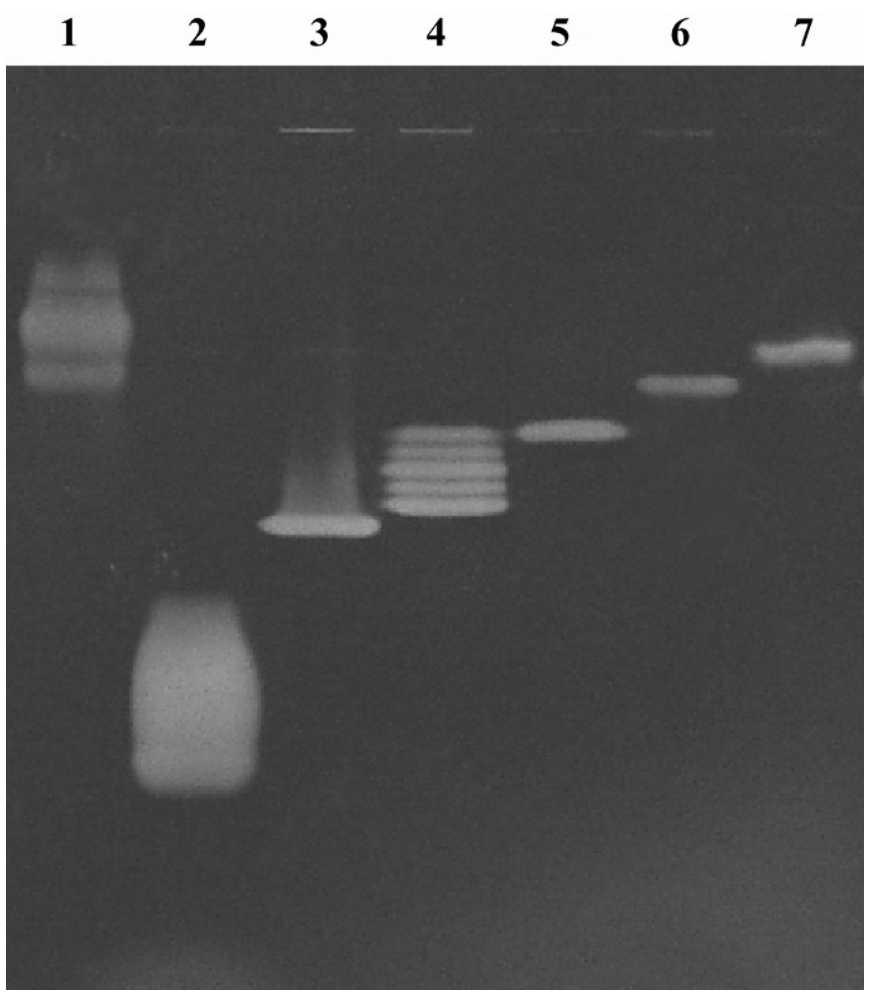

Figure 1. Activity staining on nondenaturing polyacrylamide gel. Lane 1, the commercial bile salt hydrolase from Clostridium perfringens; lane 2, Bifidobacterium infantis KL412; lane 3, Bifidobacterium longum ATCC 15708; lane 4, Lactobacillus acidophilus ATCC 43121; lane 5, L. acidophilus ATCC 53673; lane 6, L. acidophilus ATCC 53546; lane 7, L. acidophilus LAMA.

by a fast protein liquid chromatography (FPLC) system equipped with hydrophobic interaction, anion exchange, and size exclusion chromatography columns. Concentrated cell-free extracts from ammonium sulfate fractionation (40 to $80 \%$ saturation) were passed through HIC columns. Two types of BSH showed different elution profiles from HIC columns, suggesting that they might have different hydrophobic characteristics on the protein structure. Each enzyme seems to show different selectivity from other proteins depending on the HIC columns. Whereas a type A enzyme showed a better selectivity with aliphatic ligand columns (HiTrap Octyl FF or Butyl FF), a type C enzyme was more efficiently separated on aromatic ligand columns (HiTrap Phenyl FF). In each combination, the BSH were eluted near the end of the ammonium sulfate gradient with a good resolution.

The pooled fractions from the HIC column were loaded onto a Mono Q anion-exchanger column after the buffer was changed with $50 \mathrm{~m} M$ bis-Tris propane buffer ( $\mathrm{pH}$ 6.5). From the Mono Q column, BSH were eluted differently depending on the strain. For the type $\mathrm{C}$ BSH enzyme, the activity was eluted at an $\mathrm{NaCl}$
A

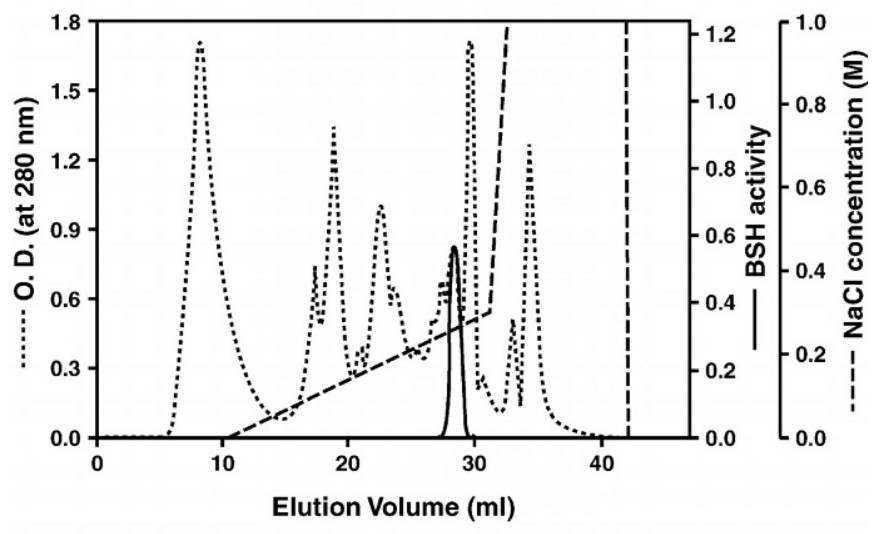

B

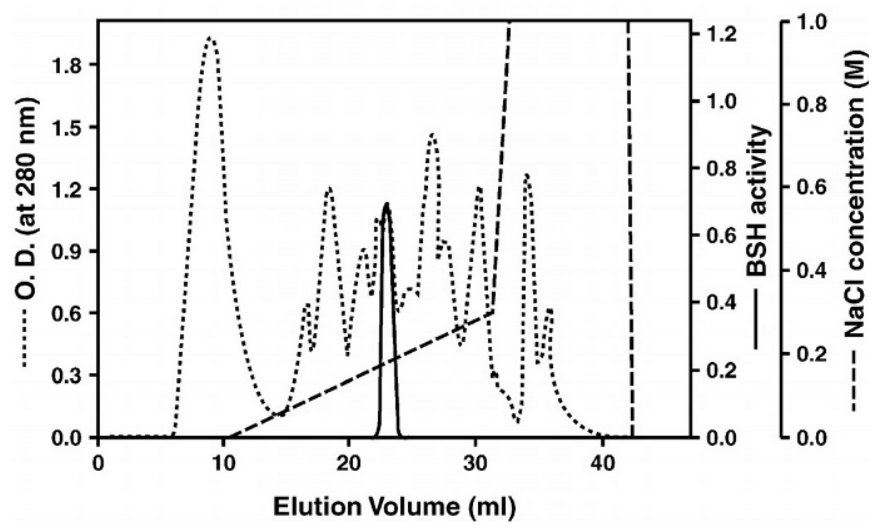

Figure 2. Elution profile of bile salt hydrolase (BSH) enzymes from an anionic-exchange column, Mono Q HR 5/5. A) Cell-free extract of Bifidobacterium longum ATCC 15708, and B) Cell-free extract of Bifidobacterium infantis KL412. Protein concentration (-), BSH activity (-), and $\mathrm{NaCl}$ gradient (----).

concentration between 0.12 and $0.16 M$ (Figure 2B). In the case of type $\mathrm{A}$, the protein was eluted between 0.23 and $0.27 \mathrm{M} \mathrm{NaCl}$ (Figure 2A) with an exception of BSH from $B$. bifidum ATCC 11863, which was eluted around $0.35 \mathrm{M} \mathrm{NaCl}$ (data not shown). Based on this different elution profile from Mono Q, B. bifidum ATCC 11863 was reclassified as type $\mathrm{B}$.

The electrophoretogram of the active fractions during purification steps and the purified BSH are shown in Figure 3. After consecutive purification steps of HIC and ion-exchange chromatography (IEC), type $\mathrm{C} \mathrm{BSH}$ was the major protein in the active fraction (Figure $3 \mathrm{~A}$ ), and this fraction was further purified using size exclusion chromatography. For the type A BSH enzyme, 2 steps of chromatography (HIC and IEC) were enough to purify the enzyme to electrophoretic homogeneity (Figure 3B).

The purification steps of three different types of $\mathrm{BSH}$ are summarized in Table 1 . The enzymes were purified 


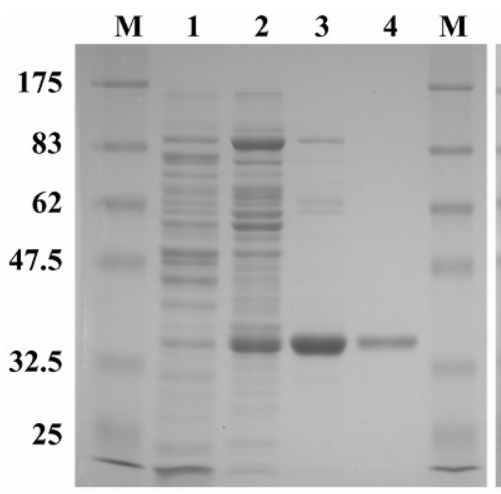

(A)

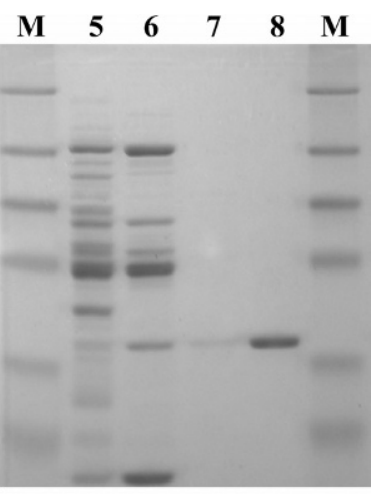

(B)
Figure 3. SDS-PAGE of cell extracts at each purification steps. Lane M, molecular weight marker; lanes 1 through 4: active fractions from Bifidobacterium infantis KL 412 (1, cell extract; 2, hydrophobic interaction [HIC]; 3 , ion-exchange chromatography [IEC]; 4, size exclusion chromatography); lanes 5 through 8: active fractions from Bifidobacterium longum ATCC 15708 (5, cell extract; 6, HIC; 7, IEC; 8 , concentrated sample of 7 ).

$30-, 34-$, and 22-fold with overall yields of 27, 29, and $25 \%$ for the types A, B, and C, respectively.

Approximately 35 -kDa protein was evident throughout the different chromatography steps, and this protein formed a single band after size exclusion chromatography (Figure $3 \mathrm{~A}$ and $\mathrm{B}$ ).

\section{pl Determination and $\mathrm{N}$-Terminal Amino Acid Sequencing}

By using an IEF system equipped with a broad $\mathrm{pH}$ range strip ( $\mathrm{pH} 4.0$ to $7.0,13 \mathrm{~cm}$ ), the approximate $\mathrm{pI}$ values were found to be between $\mathrm{pH} 4.0 \sim 5.0$. To measure more accurate $\mathrm{pI}$ values, a narrow $\mathrm{pH}$ range strip (pH 4.0 to $5.0,18 \mathrm{~cm}$ ) was used. Among 4 BSH enzymes tested, only type B BSH from B. bifidum ATCC 11863 had a pI of 4.45 and the other BSH (types A and C) from B. longum KL507, B. longum KL515, and B. infantis KL412 had similar pI values around 4.65 (Figure 4).

For the N-terminal sequencing, a type A BSH (from $B$. longum ATCC 15708) and a type C BSH (from $B$. infantis KL412) were selected. N-Terminal amino acid sequencing for the protein purified from each strain resulted in the following sequences: XTGVRFSDDEGNTYFGRNLD and XTAVRFDDGQNNMYFGRNLD, respectively. In both cases, the first $\mathrm{N}$-terminal amino acid was not identified under the experimental conditions used.

\section{Substrate Specificity}

Bile salt hydrolase enzymes purified from Bifidobacterium strains showed a broad substrate range for 6 major human bile salts. Type A and C BSH enzymes showed the highest enzyme activity with glycodeoxycholic acid (defined as 100\% activity), and they exhibited a preference for glycine-conjugated bile salts over taurine-conjugated forms (Figure 5). This tendency of preference was apparent in the case of type $\mathrm{C}$ than type A, but no difference was observed for di- or trihydroxyconjugated bile salts.

\section{DISCUSSION}

Wide distribution and high enzyme activity of $\mathrm{BSH}$ in the genus of Bifidobacterium has been reported by

Table 1. Purification of bile salt hydrolase from three strains of Bifidobacterium that are harboring different types of bile salt hydrolase enzyme.

\begin{tabular}{|c|c|c|c|c|c|}
\hline Step & $\begin{array}{l}\text { Total } \\
\text { protein } \\
(\mathrm{mg})\end{array}$ & $\begin{array}{l}\text { Total } \\
\text { activity }{ }^{1} \\
\text { (U) }\end{array}$ & $\begin{array}{l}\text { Specific } \\
\text { activity } \\
\text { (U/mg) }\end{array}$ & $\begin{array}{l}\text { Recovery } \\
(\%)\end{array}$ & $\begin{array}{l}\text { Purification } \\
\text { (fold) }\end{array}$ \\
\hline \multicolumn{6}{|c|}{ Bifidobacterium longum KL 515 (type A) } \\
\hline Crude extract & 79.7 & 20767 & 261 & 100.0 & 1.0 \\
\hline Ammonium sulphate & 69.5 & 19426 & 280 & 93.5 & 1.1 \\
\hline HIC (Butyl FF) ${ }^{2}$ & 5.1 & 16351 & 3206 & 78.7 & 12.3 \\
\hline Mono $\mathrm{Q}^{3}$ & 0.7 & 5533 & 7904 & 26.6 & 30.3 \\
\hline \multicolumn{6}{|c|}{ Bifidobacterium bifidum ATCC 11863 (type B) } \\
\hline Crude extract & 70 & 12885 & 184 & 100.0 & 1.0 \\
\hline Ammonium sulphate & 62.4 & 11914 & 191 & 92.5 & 1.0 \\
\hline HIC (Butyl FF) & 4.6 & 10376 & 2256 & 80.6 & 12.3 \\
\hline Mono Q & 0.6 & 3761 & 6168 & 29.2 & 33.5 \\
\hline \multicolumn{6}{|c|}{ Bifidobacterium infantis KL 412 (type C) } \\
\hline Crude extract & 43.5 & 10842 & 249 & 100.0 & 1.0 \\
\hline Ammonium sulphate & 38.6 & 9749 & 253 & 89.9 & 1.0 \\
\hline HIC (Phenyl FF) ${ }^{4}$ & 5.3 & 7965 & 1503 & 73.5 & 6.0 \\
\hline Mono Q & 0.5 & 2691 & 5382 & 24.8 & 21.6 \\
\hline
\end{tabular}

\footnotetext{
${ }^{1}$ One unit of enzyme activity is defined as the amount of enzyme that liberated $1 \mu \mathrm{mol}$ of amino acids from sodium glycocholate per minute.

${ }^{2,4} \mathrm{HIC}$ (Butyl FF) or HIC (Phenyl FF): Hydrophobic interaction (HiTrap) columns.

${ }^{3}$ Mono Q: Anion-exchange column.
} 


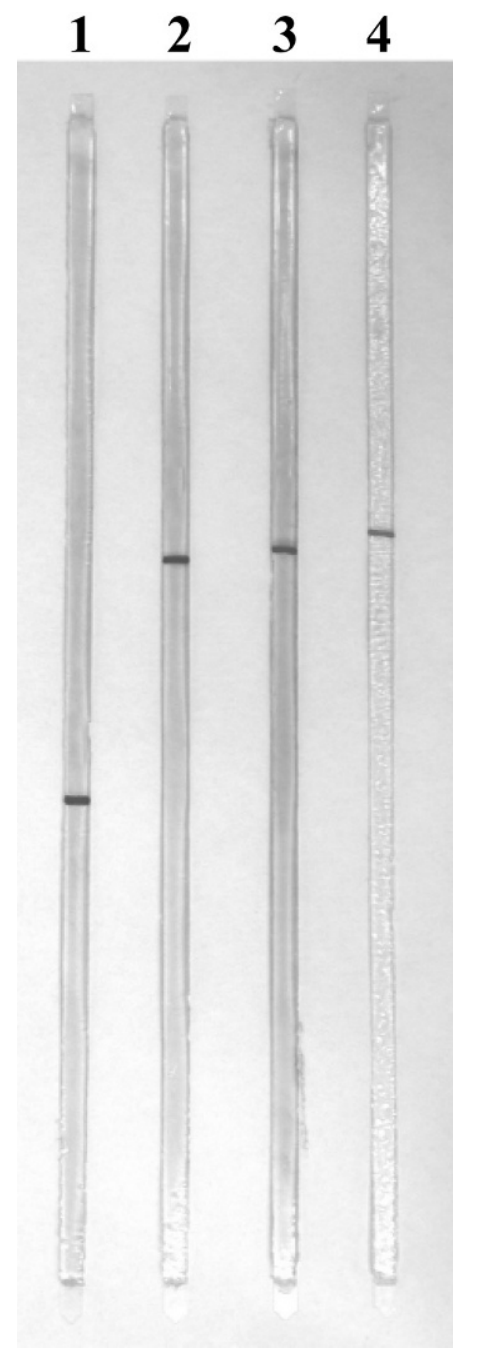

Figure 4. Isoelectric point of BSH enzymes from Bifidobacterium bifidum ATCC 11863 (lane 1), Bifidobacterium infantis KL412 (lane 2), Bifidobacterium longum KL507 (lane 3), and B. longum KL515 (lane 4). $\mathrm{pH}$ gradient on the strip; from $\mathrm{pH} 5.0$ at the top to $\mathrm{pH} 4.0$ at the bottom.

other research groups (Grill et al., 1995b, 2000b; Tanaka et al., 1999), and this fact was also confirmed from the previous experiment carried out in this laboratory. For the first time, it was demonstrated that BSH enzymes originating from the strains of the genus Bifidobacterium show different characteristics depending on the type of enzyme. Some type-specific characteristics of BSH enzymes were investigated in this study (Table 2).

Different electrophoretic migration of BSH was visualized at the position of the enzyme on Native-PAGE followed by the activity staining. This activity staining technique has been used to determine the electrophoretic mobility of BSH from Bifidobacterium strains (Grill et al., 1995b; Grill and Schneider, 1997) and a $L$. amylovorus strain (Grill et al., 2000a). However, no

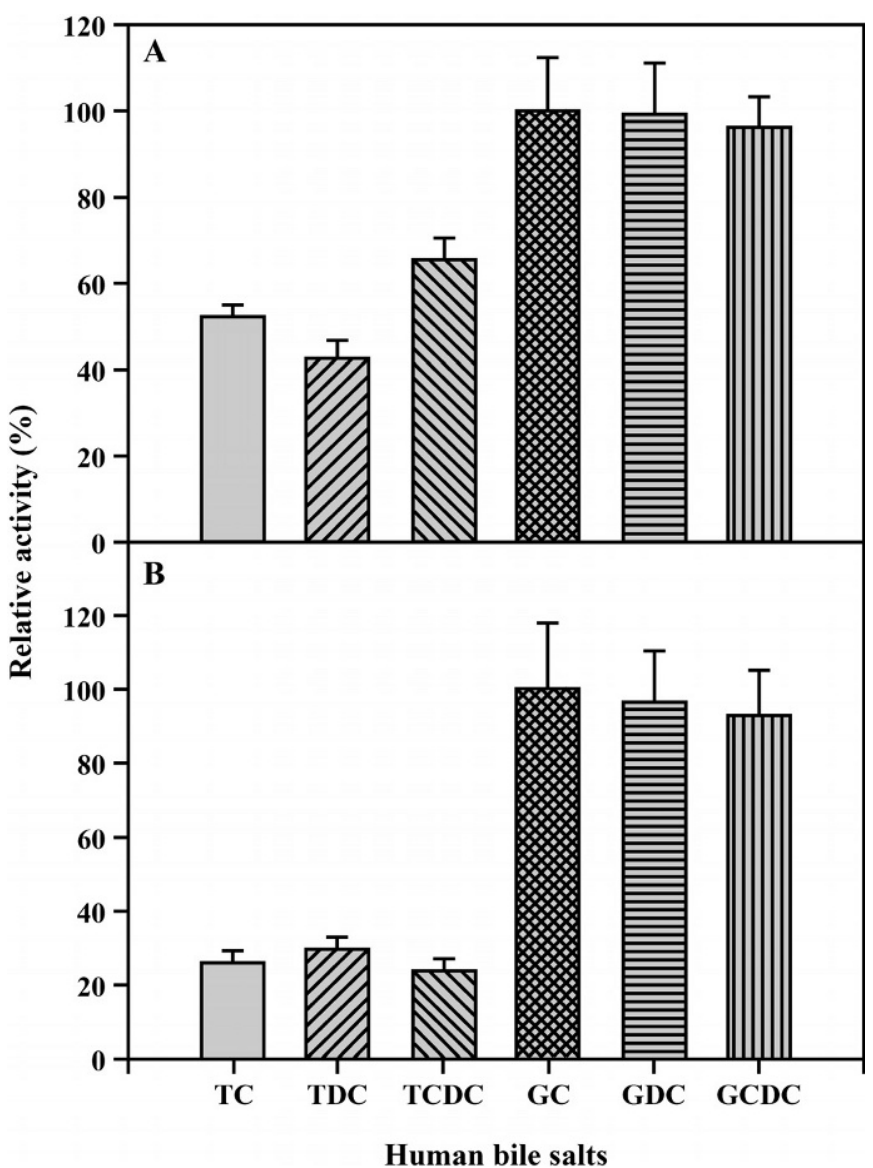

Figure 5. Substrate specificity of bile salt hydrolase enzymes from Bifidobacterium longum ATCC 15708 (A) and Bifidobacterium infantis KL 412 (B). Six major human bile salts: TC, taurocholic acid; TDC, taurodeoxycholic acid; TCDC, taurochenodeoxycholic acid; GC, glycocholic acid; GDC, glycodeoxycholic acid; GCDC, glycochenodeoxycholic acid).

approach has been made to see at the intergenus level, and no picture of the activity staining has been reported so far. By using the same experimental condition, it was possible to compare the electrophoretic mobility of the BSH enzymes from a different genus of microorganism (Figure 1). The lowest migration of BSH from $C$. perfringens is not surprising, because the higher native molecular mass $(250 \mathrm{kDa})$ has been reported from $C$. perfringens (Gopal-Srivastava and Hylemon, 1988).

Four different electrophoretic migration patterns were revealed from the genus Lactobacillus. Interestingly, 5 consecutive BSH activity bands were identified from $L$. acidophilus ATCC 43121 (lane 4 in Figure 2.). Corzo and Gilliland (1999) reported that the intracellular BSH enzyme from this strain had higher activity than other strains tested, and the molecular mass of the enzyme was estimated as $126 \mathrm{kDa}$ by gel filtration chromatography. Further study must be carried out to 
Table 2. Summary of some biochemical characteristics of purified bile salt hydrolases from different strains of Bifidobacterium.

\begin{tabular}{|c|c|c|c|c|c|c|c|}
\hline & \multirow[b]{2}{*}{$\mathrm{R}_{\mathrm{f}}$ value $^{1}$} & \multirow{2}{*}{$\begin{array}{l}\text { Elution } \\
\text { from mono } \\
\mathrm{Q}^{2}\end{array}$} & \multirow[b]{2}{*}{$\mathrm{pI}^{3}$} & \multicolumn{2}{|c|}{$\mathrm{Mw}(\mathrm{kDa})$} & \multirow{2}{*}{$\begin{array}{l}\text { N-Terminal } \\
\text { amino acid } \\
\text { homology }\end{array}$} & \multirow[b]{2}{*}{ Type } \\
\hline & & & & Sub-unit ${ }^{5}$ & Native $^{7}$ & & \\
\hline B. longum SBT2928 & & $0.33 \sim 0.36 M$ & $4.71^{4}$ & $35.024^{6}$ & $125 \sim 130$ & 20 & A \\
\hline B. longum ATCC 15708 & 0.47 & $0.23 \sim 0.27 \mathrm{M}$ & & 35 & $140 \sim 150$ & $20 / 20$ & A \\
\hline B. longum KL 515 & 0.47 & $0.23 \sim 0.27 \mathrm{M}$ & 4.65 & 35 & $140 \sim 150$ & $20 / 20$ & A \\
\hline B. bifidum ATCC 11863 & 0.50 & $0.35 \sim 0.38 M$ & 4.45 & 35 & $140 \sim 150$ & $19 / 20$ & B \\
\hline B. infantis KL 412 & 0.75 & $0.12 \sim 0.16 M$ & 4.63 & 35 & $130 \sim 140$ & $14 / 20$ & $\mathrm{C}$ \\
\hline B. longum KL 507 & 0.75 & $0.12 \sim 0.16 M$ & 4.63 & 35 & $130 \sim 140$ & $\ldots$ & $\mathrm{C}$ \\
\hline
\end{tabular}

${ }^{1} \mathrm{R}_{\mathrm{f}}$ value of major activity band on a native PAGE.

${ }^{2} \mathrm{NaCl}$ concentration $(M)$.

${ }^{3} \mathrm{pI}$ value determined by isoelectric focusing.

${ }^{4}$ Deduced $\mathrm{pI}$ value based on the nucleotide sequence.

${ }^{5}$ Determined by SDS-PAGE.

${ }^{6}$ Deduced molecular weight based on the nucleotide sequence.

${ }^{7}$ Determined by gel filtration chromatography.

${ }^{8}$ Number of identical amino acid to the BSH of B. longum SBT2928.

${ }^{9}$ Typing of BSH enzymes based on the biochemical characteristics from purification study.

investigate whether those 5 consecutive activity bands are due to hetero-isoenzymes combined with two different subunits $\alpha$ and $\beta$ as reported in L. johnsonii 100100 (Lundeen and Savage, 1992; Elkins et al., 2001).

The electrophoretic migration of BSH enzymes from Bifidobacterium strains was higher than that of Clostridium and Lactobacillus. Based on the electrophoretic mobility from the activity staining, Grill and Schneider (1997) reported 5 classes of BSH from animal and human origin strains of Bifidobacterium. They proposed that the different property of BSH electrophoretic mobility might be used to differentiate bifidobacterial species, in particular, differentiation between $B$. longum and $B$. animalis was proposed. From human origin strains tested in this study, 2 major types (A and C) were revealed. The mobility of the major band of type A BSH (lane 3 in Figure 2) was lower than that of type C (lane 2 in Figure 2).

Chromatographic steps were optimized in this study using an FPLC system equipped with 3 different types of columns for the purification of three different types of BSH from bifidobacteria strains. Hydrophobic interaction chromatography was appropriate as the first step of the purification, since no buffer change was necessary after ammonium sulphate precipitation. Furthermore, HIC showed high selectivity and high resolution for the $\mathrm{BSH}$ enzyme at the end of ammonium sulphate, and the high purification fold was obtained after this chromatographic step (Table 1). The BSH enzyme was eluted from the HIC column at a low concentration of ammonium sulphate, suggesting that the BSH enzyme belongs to a group of hydrophobic proteins. Considering some hydrophobic characteristics in their steroid ring structure of the substrates (bile salts), it is speculated that some hydrophobic amino acid residues on the surface of a BSH enzyme play a major role in binding via hydrophobic interactions. The similar phenomenon was reported by Alkema et al. (2002) from penicillin acylase, which has been proposed as the same Ntn-hydrolase superfamily (Suresh et al., 1999; Oinonen and Rouvinen, 2000).

Three types of BSH (A, B, and C) showed different elution profiles from anion exchanger Mono $\mathrm{Q}$, suggesting that $\mathrm{BSH}$ enzymes of different types have some differences in their amino acid compositions, charge characteristics, as well as their tertiary and quaternary protein structures. Such a difference in the elution pattern has been reported previously. Where BSH from $B$. longum BB 536 was eluted between 0.11 and $0.15 \mathrm{M}$ $\mathrm{NaCl}$ (Grill et al., 1995b), BSH from B. longum SBT 2928 was eluted between 0.33 and $0.36 \mathrm{M} \mathrm{NaCl}$ using Na-phosphate buffer system (Tanaka et al., 2000). Compared to Na-phosphate buffer (an anionic buffer with $\mathrm{Na}^{+}$as counter-ions), bis-Tris propane (a cationic buffer with $\mathrm{Cl}^{-}$as counter-ions), which was used in this study, eluted proteins more efficiently from the anion-exchanger column. A different elution pattern from the Mono Q column was confirmed by measuring the fructose-6-phosphate phosphoketolase (F6PPK) enzyme activity as a marker protein. Regardless of types, F6PPK enzyme, which is a unique enzyme in bifidobacteria, was eluted at $\mathrm{NaCl}$ concentration between 0.30 and $0.34 M$. This observation is similar to that made for the F6PPK enzyme, which was reported by Grill et al. (1995a).

The subunit molecular masses estimated by SDSPAGE analyses were around $35 \mathrm{kDa}$ for all $\mathrm{BSH}$ enzymes in this study. Numerous enteric bacteria express 
BSH activity, and there are differences in the molecular structure (trimeric, tetrameric, or hexameric proteins with a molecular mass of 105,000 to 250,000 ) (Stellwag and Hylemon, 1976; Gopal-Srivastava and Hylemon, 1988; Coleman and Hudson, 1995; Grill et al., 1995b). The BSH of type $\mathrm{C}$ showed a little lower native molecular mass (130 to $140 \mathrm{kDa}$ ) than that of type A and B $(140$ to $150 \mathrm{kDa})$. This is in good agreement with those of other BSH enzymes reported previously and indicates that the native enzyme is a tetramer (Tanaka et al., 2000).

The measured $\mathrm{pI}$ values were close to the theoretical $\mathrm{pI}$ of 4.51 for the deduced protein of BSH from $B$. longum SBT 2928 (Tanaka et al., 2000). Isoelectric points of BSH enzymes from the genus Bifidobacterium were found to be lower than the values reported from the others; 5.29 for BSH from L. acidophilus KS-13 (GenBank accession number AAD03709), 4.98 from L. gasseri (GenBank accession number ZP_00046789), 5.05 and 4.88 from $L$. johnsonii 100-100 alpha and beta (GenBank accession numbers AAG22541 and AAC34381, respectively), and 5.12 from $L$. plantarum WCFS1 (GenBank accession number NP_786739). The lower pI value of BSH from bifidobacterial strains implies that the BSH enzymes contain a higher portion of negatively charged residues (Asp + Glu) and a lower portion of positively charged residues (Arg + Lys). In fact, the ratio of negatively charged residues to positively charged residues is $2.05(41 / 20)$ and 1.21 (35/29) in the amino acid composition of the BSH enzymes from $B$. longum and L. acidophilus, respectively.

Even though the last $\mathrm{N}$-terminal amino acid was not identified under the experimental condition used, the Cys residue at the $\mathrm{N}$-terminal end was highly conserved in all BSH enzymes except one BSH enzyme purified from Xanthomonas maltophilia (Dean et al., 2002). Elkin et al. (2001) and Tanaka et al. (2000) have proposed that the Cys residue at the $\mathrm{N}$-terminal end of the BSH enzyme as one of the active sites of the enzyme. From a protein homology comparison, these $\mathrm{N}$-terminal sequences were homologous to those of several lactobacilli as well as Clostridium perfringens. In addition, an amino acid motif, XYFGRNLDX, which was highly conserved within all BSH enzymes reported in lactobacilli and bifidobacteria, was presented in both N-terminal sequences of type $\mathrm{A}$ and type $\mathrm{C}$ enzymes.

In this study, BSH from all strains of Bifidobacterium showed a higher deconjugation rate on glycine conjugated bile salts than on taurine conjugated forms. Considering the fact that the majority of human bile salts are glycine conjugated forms, BSH enzymes from bifidobacterial strains might be important in the deconjugation of bile salt in the human intestine.
From the foregoing discussion, one may conclude that the optimized purification conditions established with HIC and Mono Q columns were very effective in purifying three types of active BSH from bifidobacteria strains. Purified BSH enzymes from different strains showed some type-specific characteristics, and they had some different characteristics from those of other genus and species. Migration patterns on the PAGE gel and elution profiles from the anion-exchange column described in this study could be useful for the investigation of the similarities and differences among BSH enzymes from different genus and species. Because almost every strain of bifidobacteria possesses BSH enzyme activity at a significant level, and they have some genusspecific and type-specific characteristics, this phenotypic trait may be used as a means of phenotypic characterization of Bifidobacterium strains.

For the molecular characterization of type A, B, and $\mathrm{C}$ enzymes, the cloning of the BSH gene is currently being carried out. Once the nucleotide sequences for each type of $b s h$ gene is obtained from the cloning experiment, it will provide some information about the phylogenetic relationship within the genus of Bifidobacterium as well as other genus and species of enteric bacteria that are harboring $b s h$ gene. Furthermore, it will allow us to develop some genus-specific and type-specific probes based on the BSH locus and to use them as useful identification tools.

\section{ACKNOWLEDGMENTS}

This research was supported by a research operating grant from the Natural Sciences and Engineering Research Council of Canada (NSERC-222026). G.-B. Kim is the recipient of a Fonds pour la Formation de Chercheurs et l'Aide a la Recherche (FCAR) scholarship from the government of Quebec.

\section{REFERENCES}

Ahn, Y. T., G.-B. Kim, K. S. Lim, Y. J. Baek, and H. U. Kim. 2003. Deconjugation of bile salts by Lactobacillus acidophilus isolates. Int. Dairy J. 13:303-311.

Alkema, W. B., A.-J. Dijkhuis, E. de Vries, and D. B. Janssen. 2002. The role of hydrophobic active-site residues in substrate specificity and acyl transferase activity of penicillin acylase. Eur. J. Biochem. 269:2093-2100.

Anderson, J. W., and S. E. Gilliland. 1999. Effect of fermented milk (yogurt) containing Lactobacillus acidophilus L1 on serum cholesterol in hypercholesterolemic humans. J. Am. College Nutr. 18:43-50.

Coleman, J. P., and L. L. Hudson. 1995. Cloning and characterization of a conjugated bile acid hydrolase gene from Clostridium perfringens. Appl. Environ. Microbiol. 61:2514-2520.

Corzo, G., and S. E. Gilliland. 1999. Bile salt hydrolase activity of three strains of Lactobacillus acidophilus. J. Dairy Sci. 82:472-480.

Dean, M., C. Cervellati, E. Casanova, M. Squerzanti, V. Lanzara, A. Medici, P. P. de Laureto, and C. M. Bergamini. 2002. Character- 
ization of cholylglycine hydrolase from a bile-adapted strain of Xanthomonas maltophilia and its application for quantitative hydrolysis of conjugated bile salts. Appl. Environ. Microbiol. 68:3126-3128.

De Rodas, B. Z., S. E. Gilliland, and C. V. Maxwell. 1996. Hypocholesterolemic action of Lactobacillus acidophilus ATCC 43121 and calcium in swine with hypercholesterolemia induced by diet. J. Dairy Sci. 79:2121-2128.

De Smet, I., P. De Boever, and W. Verstraete. 1998. Cholesterol lowering in pigs through enhanced bacterial bile salt hydrolase activity. Br. J. Nutr. 79:185-194.

De Smet, I., L. van Hoorde, N. De Saeyer, M. vande Woewtyne, and W. Verstraete. 1994. In vitro study of bile salt hydrolase (BSH) activity of BSH isogenic Lactobacillus plantarum 80 strains and estimation of cholesterol lowering through enhanced BSH activity. Microb. Ecol. Health Dis. 7:315-329.

Dussurget, O., D. Cabanes, P. Dehoux, M. Lecuit, C. Buchrieser, P. Glaser, and P. Cossart. 2002. Listeria monocytogenes bile salt hydrolase is a virulence factor involved in the intestinal and hepatic phases of listeriosis. Mol. Microbiol. 45:1095-1106.

du Toit, M., C. M. A. P. Franz, L. M. T. Dicks, U. Schillinger, P. Haberer, B. Warlies, F. Ahrens, and W. H. Holzapfel. 1998. Characterisation and selection of probiotic lactobacilli for a preliminary minipig feeding trial and their effect on serum cholesterol levels, faeces $\mathrm{pH}$ and faeces moisture content. Int. J. Food Microbiol. 40:93-104.

Elkins, C., and D. C. Savage. 1998. Identification of genes encoding conjugated bile salt hydrolase and transport in Lactobacillus johnsonii 100-100. J. Bacteriol. 180:4344-4349.

Elkins, C. A., S. A. Moser, and D. C. Savage. 2001. Genes encoding bile salt hydrolases and conjugated bile salt transporters in Lactobacillus johnsonii 100-100 and other Lactobacillus species. Microbiology 147:3404-3412.

Gopal-Srivastava, R., and P. B. Hylemon. 1988. Purification and characterization of conjugated bile salt hydrolase from Clostridium perfringens. J. Lipid Res. 29:1079-1085.

Grill, J. P., C. Cayuela, J. M. Antoine, and F. Schneider. 2000a. Isolation and characterization of a Lactobacillus amylovorus mutant depleted in conjugated bile salt hydrolase activity: Relation between activity and bile salt resistance. J. Appl. Microbiol. 89:553-563.

Grill, J. P., J. Crociani, and J. Ballongue. 1995a. Characterization of fructose 6 phosphate phosphoketolases purified from Bifidobacterium species. Curr. Microbiol. 31:49-54.

Grill, J. P., S. Perrin, and F. Schneider. 2000b. Bile salt toxicity to some bifidobacteria strains: Role of conjugated bile salt hydrolase and $\mathrm{pH}$. Can. J. Microbiol. 46:878-884.

Grill, J. P., and F. Schneider. 1997. Characterization of Bifidobacterium species based on bile salt hydrolase localization and electrophoretic mobility. Microbiologie-Aliments-Nutrition 15:307-313.
Grill, J. P., F. Schneider, J. Crociani, and J. Ballongue. 1995b. Purification and characterization of conjugated bile salt hydrolase from Bifidobacterium longum BB536. Appl. Environ. Microbiol. 61:2577-2582.

Gunn, J. S. 2000. Mechanisms of bacterial resistance and response to bile. Microbes Infect. 2:907-913.

Kim, G.-B., J. H. Lee, K. S. Lim, C. S. Huh, H. S. Bae, Y. J. Baek, and H. U. Kim. 1999. Bile salts deconjugation activity of Lactobacillus strains isolated from yogurt products. Kor. J. Appl. Microbiol. Biotechnol. 27:385-390.

Knarreborg, A., R. M. Engberg, S. K. Jensen, and B. B. Jensen. 2002. Quantitative determination of bile salt hydrolase activity in bacteria isolated from the small intestine of chickens. Appl. Environ. Microbiol. 68:6425-6428.

Laemmli, U. K. 1970. Cleavage of structural proteins during the assembly of the head of bacteriophage T4. Nature 227:680-685.

Lundeen, S., and D. C. Savage. 1992. Multiple forms of bile salt hydrolase from Lactobacillus sp. strain 100-100. J. Bacteriol. 174:7217-7220.

Oinonen, C., and J. Rouvinen. 2000. Structural comparison of Ntnhydrolases. Protein Sci. 9:2329-2337.

Pereira, D. I. A., and G. R. Gibson. 2002. Cholesterol assimilation by lactic acid bacteria and bifidobacteria isolated from the human gut. Appl. Environ. Microbiol. 68:4689-4693.

Singh, J., R. Hamid, and B. S. Reddy. 1997. Dietary fat and colon cancer: modulating effect of types and amount of dietary fat on ras-p21 function during promotion and progression stages of colon cancer. Cancer Res. 57:253-258.

Stellwag, E. J., and P. B. Hylemon. 1976. Purification and characterization of bile salt hydrolase from Bacteroides fragilis subsp. fragilis. Biochim. Biophys. Acta 452:165-176.

Suresh, C. G., A. V. Pundle, H. SivaRaman, K. N. Rao, J. A. Brannigan, C. E. McVey, C. S. Verma, Z. Dauter, E. J. Dodson, and G. G. Dodson. 1999. Penicillin V acylase crystal structure reveals new Ntn-hydrolase family members. Nature Struct. Biol. 6:414-416.

Tanaka, H., K. Doesburg, T. Iwasaki, and I. Mierau. 1999. Screening of lactic acid bacteria for bile salt hydrolase activity. J. Dairy Sci. 82:2530-2535.

Tanaka, H., H. Hashiba, J. Kok, and I. Mierau. 2000. Bile salt hydrolase of Bifidobacterium longum-biochemical and genetic characterization. Appl. Environ. Microbiol. 66:2502-2512.

Thomas, L. A., M. J. Veysey, T. Bathgate, A. King, G. French, N. C. Smeeton, G. M. Murphy, and R. H. Dowling. 2000. Mechanism for the transit-induced increase in colonic deoxycholic acid formation in cholesterol cholelithiasis. Gastroenterology 119:806-815.

Usman and A. Hosono. 1999. Bile tolerance, taurocholate deconjugation, and binding of cholesterol by Lactobacillus gasseri strains. J. Dairy Sci. 82:243-248. 